\title{
Effect of acute kidney injury on weaning from mechanical ventilation in chronic obstructive pulmonary diseases patients with respiratory failure
}

\author{
Ahmed Gouda El-Gazzar, Mahmoud Mohamad El-Salahy, Tarek Samy Essway, Samar Nasef Mohammed and \\ Marwa Elsayed Elnaggar ${ }^{*}$ (D)
}

\begin{abstract}
Background: Acute kidney injury (AKI) worsens the outcome in mechanically ventilated patients. The occurrence of AKI may have an effect on weaning from mechanical ventilation (MV). The purpose of this work is to study the effect of AKI on weaning from MV for chronic obstructive pulmonary disease (COPD) patients with respiratory failure (RF). The study included 100 mechanically ventilated COPD patients with RF. Patients were classified into group 1, mechanically ventilated COPD patients with type 2 RF who developed AKI, and group 2, mechanically ventilated COPD patients with type 2 RF, who did not develop AKI.

Results: The age of the studied group ranged between 46 and 80 years, and serum creatinine on admission was within normal. There is a significant difference in a serum creatinine level after 2 days and after 1 week of MV in an intensive care unit (ICU) among AKI cases. There is a significant difference in weaning success between AKI and non-AKI patients with much higher weaning success in non-AKI group. Also, there is a significant reduction in glomerular filtration rate (GFR) in AKI patients after $48 \mathrm{~h}$ of admission.
\end{abstract}

Conclusions: AKI is frequent in COPD patients within $48 \mathrm{~h}$ of ICU admission and MV increases the risk of AKI in COPD patients.

Keywords: Acute kidney injury (AKI), Respiratory failure (RF), Chronic obstructive pulmonary diseases (COPD)

\section{Background}

Acute kidney injury (AKI) is the abrupt loss of kidney function, resulting in the retention of urea and other nitrogenous waste products and dysregulation of extracellular volume and electrolytes. It is most easily detected by measurement of the serum creatinine, which is used to estimate the glomerular filtration rate (GFR). AKI was defined as at least one measurement of serum creatinine of $>1.5 \mathrm{mg} / \mathrm{dL}$ during the ICU stay [1].

\footnotetext{
* Correspondence: marwa_141282@hotmail.com

Faculty of Medicine, Benha University, Benha city, Qalubia Province 13511, Egypt
}

The causes of AKI in the ICU are frequently "multifactorial," and in most cases, AKI develops from a com-

AKI can increase pulmonary vascular permeability and downregulate ion channels critical for fluid absorption in sectosis. The occurrence of lung injury affect renal perfusion by reducing cardiac output and stimulating hormonal and sympathetic pathways [3].

Besides that, the presence of AKI in critically ill patients like those with respiratory failure frequently contributes to 
depression of mental status and accumulation of several drug metabolites, which can further compromise the level of consciousness [4].

\section{Aim of the work}

The aim of this work was to study the effect of acute kidney injury on weaning from mechanical ventilation for COPD patients with respiratory failure including successfulness, duration of weaning, and the length of patients stay in the respiratory care unit.

\section{Methods}

The prospective study included 100 mechanically ventilated COPD patients with respiratory failure admitted at the respiratory intensive care unit of Benha University Hospitals during the period from September 2016 to May 2018.

Acute exacerbation of COPD with respiratory failure presented with one of the following:

- Respiratory acidosis $\left(\mathrm{PaCO}_{2} \geq 45 \mathrm{mmHg}\right.$ and arterial $\mathrm{pH} \leq 7.35)$

- Severe dyspnea with respiratory muscle fatigue

- Persistent hypoxemia with oxygen supplementation

These patients failed to respond to NIV (non-invasive ventilation), presented with respiratory or cardiac arrest, have decreased conscious level or hemodynamically unstable and indicated for invasive mechanical ventilation [5].

Patients were classified into 2 groups:

Group 1: mechanically ventilated COPD patients

(diagnosed according to GOLD 2017) with type 2 RF who developed acute kidney injury (AKI).

Group 2: mechanically ventilated COPD patients with type 2 RF but not developed AKI.

AKI was defined according to KDIGO as any of the following [6]:

- Increase in serum creatinine by $0.3 \mathrm{mg} / \mathrm{dL}$ or more within $48 \mathrm{~h}$

- Increase in serum creatinine to 1.5 times baseline or more within the last 7 days

Inclusion criteria:

- COPD patients with type 2 respiratory failure plus AKI after $48 \mathrm{~h}$ of starting mechanical ventilation (MV).

- Invasive MV for $>48 \mathrm{~h}$

Exclusion criteria:
Patients with (chronic kidney injury, respiratory failure due to causes other than COPD and who receiving drugs altering renal function)

All patients subjected to the following:

1- Full history taking and clinical examination

2- Plain chest X-ray

3- Routine laboratory investigations $(\mathrm{CBC}$, liver, and kidney function tests)

4- Arterial blood gases (ABG) using Sensa Core's ST200 CC Blood Gas Analyzer (Sensa Core Medical Instrumentation Pvt. Ltd. Plot No. 3, EPIP Zone, Pashamylaram, Sangareddy District, Telangana, 502307 Hyderabad, India.)

5- Assessment for AKI

A. Serum (creatinine, $\mathrm{Na}$, and $\mathrm{K}$ )

B. Estimation of GFR: through the following equations:

CKD-EPI (chronic kidney disease epidemiology collaboration); GFR $=141 \times \mathrm{min}$ $\left(\mathrm{S}_{\mathrm{cr}} / \kappa, 1\right)^{\alpha} \times \max \left(\mathrm{S}_{\mathrm{cr}} / \kappa, 1\right)^{-1.209} \times 0.993^{\mathrm{age}} \times$ 1.018 [if female] $\times 1.159$ [if black] [7].

NB: where $S_{\text {cr }}$ is serum creatinine in $\mathrm{mg} / \mathrm{dL}, \kappa$ is 0.7 for females and 0.9 for males, $\alpha$ is 0.329 for females and -0.411 for males, min indicates the minimum of $\mathrm{S}_{\mathrm{cr}} / \mathrm{K}$ or 1 , and $\max$ indicates the maximum of $\mathrm{S}_{\mathrm{cr}} / \kappa$ or 1 .

MDRD (the modification of diet in renal disease): GFR $\left(\mathrm{mL} / \mathrm{min} / 1.73 \mathrm{~m}^{2}\right)=175 \times$ $(\mathrm{Scr})-1.154 \times($ age $)-0.203 \times(0.742$ if female $)$ $\times$ (1.212 if black) [8].

6- APACHE II score calculation [9]: The point score is calculated (Table 1) from a patient's age and 12 routine physiological measurements measured during the first $24 \mathrm{~h}$ after admission including [A$\mathrm{aDO}_{2}$ or $\mathrm{PaO}_{2}$ (depending on $\mathrm{FiO}_{2}$ ), temperature (rectal), mean arterial pressure, $\mathrm{pH}$ arterial, heart rate, respiratory rate, sodium (serum), potassium (serum), creatinine, hematocrit, white blood cell count, Glasgow coma scale].

Ventilator setting for both groups [10]:

- Starting with assist control mode ventilation with a volume target

- Fraction of inspired oxygen $\left(\mathrm{FiO}_{2}\right)$ was set to target $\mathrm{SpO}_{2}$ of $88-92 \%$

- Tidal volume (VT) 6-8 ml/kg, respiratory rate (RR) 12-14/min, inspiratory: expiratory (I: E) ratio $=1: 3$

Table 1 Interpretation of score

\begin{tabular}{lllllllll}
\hline Score & $0-4$ & $5-9$ & $10-14$ & $15-19$ & $20-24$ & $25-29$ & $30-34$ & $>34$ \\
Death rate (\%) & 4 & 8 & 15 & 25 & 40 & 55 & 75 & 85 \\
\hline
\end{tabular}


Table 2 Comparison of serum creatinine level in the studied groups on admission, after 2 days and after 1 week of starting mechanical ventilation

\begin{tabular}{|c|c|c|c|c|}
\hline Serum creatinine $(\mathrm{mg} / \mathrm{dl})$ & $\begin{array}{l}\text { Non AKI (no. = 42) } \\
\text { mean } \pm \text { SD }\end{array}$ & $\begin{array}{l}\text { AKI }(\text { no. }=58) \\
\text { mean } \pm S D\end{array}$ & Test & $P$ value \\
\hline On admission & $0.84 \pm 0.18$ & $0.94 \pm 0.21$ & $t=1.79$ & 0.08 \\
\hline After $48 \mathrm{~h}$ of $\mathrm{MV}$ & $0.82 \pm 0.15$ & $2.0 \pm 0.27$ & $t=17.80$ & $<0.001(\mathrm{HS})$ \\
\hline After 1 week of MV & $0.89 \pm 0.17$ & $2.05 \pm 0.47$ & $t=10.78$ & $<0.001(\mathrm{HS})$ \\
\hline
\end{tabular}

$A K I$ acute kidney injury, $M V$ mechanical ventilation

or more, flow rate $80-100 \mathrm{~L} / \mathrm{min}$, peak inspiratory pressure (PIP) of $<40-45 \mathrm{~cm} \mathrm{H}_{2} \mathrm{O}$ and Pplat $<30$ $\mathrm{cm} \mathrm{H}_{2} \mathrm{O}$ was acceptable

- PEEP setting and inspiratory pressure support started at $5 \mathrm{~cm} \mathrm{H}_{2} \mathrm{O}$ and $10 \mathrm{~cm} \mathrm{H}_{2} \mathrm{O}$, respectively.

\section{Ethics approval and consent}

The Research Ethics Committee at the Faculty of Medicine, Benha University, has approved the study, and all patients provided written informed consent before participation

\section{Statistical analysis}

All data were collected, tabulated, and statistically analyzed using STATA/SE version 11.2 for Windows (STATA Corporation, College Station, Texas). Continuous data were expressed as the mean \pm SD and range, and categorical data were expressed as a number and percentage. Student $t$ test $(t)$ and Mann-Whitney test $(z)$ were used to compare two groups of normally and nonnormally distributed data, respectively. One-way analysis of variance (ANOVA; $F$ ) and Kruskal-Wallis test $\left(x^{2}\right)$ were used to compare more than two groups. Percent of categorical variables was compared using the chi-square $\left(\chi^{2}\right)$ test and Fisher's exact test as appropriate. Statistical significance was accepted at $P$ value $<0.05(\mathrm{~S})$. A $P$ value $<0.001$ was considered highly significant (HS) while a $P$ value $>0.05$ was considered non-significant [11].

\section{Results}

The age of the studied group is between 46 and 80 years with males (86\%) are more than females (14\%), and serum creatinine on admission was within normal (0.9 \pm 0.2). Serum creatinine was significantly higher in COPD patients with AKI $48 \mathrm{~h}$ and 1 week following mechanical ventilation (Table 2). Weaning success in COPD patients was related to lower APACHE II score, low PEEP used during mechanical ventilation, less days in ICU, and less days on mechanical ventilation (Table 3 ). Also, the presence of AKI increased the chance of weaning difficulty and death (Table 4). APACHE II score was found to be significantly higher in COPD patients with AKI compared with patients without AKI. Also, GFR decreased $48 \mathrm{~h}$ following ICU admission in COPD patients with AKI. It was found also that, COPD with AKI required higher PEEP, more days on mechanical ventilation and more ICU stay while other ventilator parameters did not show a significant difference between COPD patients with or without AKI (Table 5, Fig. 1). About 27.59\% of COPD patients with AKI showed increased echogenicity of the kidney while 6 patients developed bilateral grade I nephropathy (Table 6).

\section{Discussion}

Many COPD patients have latent kidney injury (KI) that manifested on MV. According to Cerda et al., the prevalence of AKI within the overall COPD cohort was 128/ 100,000 person-years, the prevalence of concomitant AKI at exacerbation changed into $1.9 \%$, and the mortality rate in patients with AKI at exacerbation was 521/ 1000 person-years [12].

Regarding serum creatinine level in the studied groups, this study showed that there was a significant difference in serum creatinine levels after 2 days and after 1 week of MV in ICU among the 1st group than non-AKI group (Table 2). Vieira et al. studied 140 patients in the intensive care unit (ICU), 93 with AKI and 47 controls and

Table 3 Relation between weaning success and parameters of admission in ICU including APACHE II score

\begin{tabular}{|c|c|c|c|c|c|c|c|c|}
\hline \multirow[t]{3}{*}{ Variable } & \multicolumn{8}{|c|}{ Weaning success } \\
\hline & \multicolumn{2}{|c|}{$\begin{array}{l}\text { Weaned and discharged } \\
\text { (no. }=72)\end{array}$} & \multicolumn{2}{|c|}{$\begin{array}{l}\text { Died (mostly hypoxic arrest) } \\
(\text { no. }=22)\end{array}$} & \multicolumn{2}{|c|}{$\begin{array}{l}\text { Difficult weaning } \\
(\text { no. }=6)\end{array}$} & \multirow[t]{2}{*}{ Test } & \multirow[t]{2}{*}{$P$} \\
\hline & Mean \pm SD & Range & Mean \pm SD & Range & Mean \pm SD & Range & & \\
\hline APACHE II score & $17.36 \pm 4.73$ & $11-28$ & $25.36 \pm 6.44$ & $15-34$ & $28.33 \pm 2.89$ & $25-30$ & $F=14.97$ & $<0.001(\mathrm{HS})$ \\
\hline Mechanical ventilation parameter (PEEP) & $5 \pm 0$ & 5 & $6.36 \pm 2.01$ & $5-10$ & $9.33 \pm 2.08$ & $7-11$ & $x^{2}=10.53$ & $0.005(S)$ \\
\hline Time of stay in ICU in days & $8.97 \pm 1.98$ & $7-14$ & $10.73 \pm 2.53$ & $7-15$ & $28 \pm 2$ & $26-30$ & $x^{2}=13.07$ & $0.001(S)$ \\
\hline Time of mechanical ventilation in days & $6.03 \pm 2.05$ & $4-15$ & $8.73 \pm 2.65$ & $6-13$ & $21.67 \pm 3.78$ & $19-26$ & $X^{2}=18.78$ & $<0.001(\mathrm{HS})$ \\
\hline
\end{tabular}

ICU intensive care unit, APACHE II acute physiology and chronic health evaluation II, PEEP positive end-expiratory pressure 
Table 4 Comparison of weaning success between AKI and nonAKI cases

\begin{tabular}{llllllll}
\hline Weaning success & \multicolumn{2}{l}{ Non-AKI $($ no. $=42)$} & & \multicolumn{2}{l}{ AKI $($ no. = 58) } & $P$ \\
\cline { 2 - 3 } & No. & $\%$ & & No. & $\%$ & \\
\hline Weaned and discharged & 38 & 90.48 & & 34 & 58.62 & $0.04(\mathrm{~S})$ \\
Died & 4 & 9.52 & & 18 & 31.03 & \\
Difficult weaning & 0 & 0.0 & & 6 & 10.34 & \\
\hline
\end{tabular}

AKI acute kidney injury

demonstrated that $\geq 85 \%$ increase in baseline serum creatinine level in AKI cases [13].

This indicates that there is a rapid decline in renal function from baseline occurring over several hours resulting in the accumulation of nitrogenous wastes such as urea and creatinine [14].

In meta-analysis review by Van den Akker et al., they found that the pooled odds ratio for the overall effect of MV on AKI was 3.16 to 4.18 and that all subgroups showed that MV increases the risk of AKI. They concluded that invasive MV is associated with a threefold increase in the odds of developing AKI and various $\mathrm{Vt}$ or PEEP settings do not modify the risk [15].

In this study, there was a significant relation between weaning success and the APACHE II score as well as the time of stay in ICU. Patients with lower APACHE II score get better weaning results, less time of MV, less need to increase PEEP, and less time of stay in ICU. Difficult weaning and dead patients showed significant higher levels of PEEP needed, longer duration of ICU stay, and longer duration of MV in days (Table 3).

Vieira et al. showed that the length of ICU stays and ICU mortality rate were significantly greater in the AKI patients. After adjusting for the APACHE II score, it was higher among AKI patients $(24 \pm 8.1$ versus $20 \pm 10 ; p=$ 0.04) [13].

In another study done by Clermont et al., it was not clear whether the outcome is related to respiratory complications or duration of MV and whether even a mild AKI would be still associated with a poor outcome. They were able to demonstrate a relationship between the development of AKI in the ICU and the increase in mortality rate [16].

These results assume that reversible factors have to be optimized (e.g., renal, metabolic) that the eventual clinical outcome of patients with prolonged weaning failure will depend on the correction of the underlying disease [17].

In the current study, there was a higher percentage of weaning success in non-AKI than AKI patients. Also, difficult weaning and dead patients were significantly higher in AKI patients, meaning that the development of AKI inversely affects weaning from MV (Table 4).

Rothaar et al. showed that the duration of MV and the time spent in weaning was significantly longer in patients with AKI. The rate of weaning failure in their study is similar to known literature, around (20\%), although the weaning failure in the AKI patients was not significantly different. The exact role of AKI in lengthening the duration of weaning is not clear, but they suggested that the findings can be partially explained by the interactions of kidney injury and respiratory function [18].

The present study showed that APACHE II score was significantly higher in AKI cases than non-AKI cases reflecting the impact of AKI on the outcome of ICU admission (Table 5).

Esteban et al. studied 23 medical/surgical ICU patients with similar criteria for our patients. APACHE II score did not differ between groups, but patients who developed AKI were more severely ill in the long term.

Table 5 Relation between kidney injury and APACHE II score, MV parameters, duration of ICU stay, and GFR among the studied

\begin{tabular}{|c|c|c|c|c|c|}
\hline \multicolumn{2}{|l|}{ Variable } & \multirow{2}{*}{$\begin{array}{l}\text { Non-AKI }(\text { no. }=42) \\
\text { Mean } \pm \text { SD } \\
17.19 \pm 4.79\end{array}$} & \multirow{2}{*}{$\begin{array}{l}\text { AKI }(\text { no. }=58) \\
\text { Mean } \pm S D \\
21.65 \pm 6.77\end{array}$} & \multirow{2}{*}{$\begin{array}{l}\text { Test } \\
Z=2\end{array}$} & \multirow{2}{*}{$\begin{array}{l}P \\
0.04\end{array}$} \\
\hline APACHE I| score & & & & & \\
\hline \multirow[t]{5}{*}{ Mechanical ventilation parameters } & PEEP & $5 \pm 0$ & $5.96 \pm 1.88$ & $Z=2.39$ & $0.02(S)$ \\
\hline & $\mathrm{Vt} \mathrm{ml} / \mathrm{kg}$ & $7.05 \pm 0.74$ & $7.03 \pm 0.73$ & $Z=0.05$ & 0.9 \\
\hline & $\mathrm{RR}$ & $12 \pm 0$ & $12.38 \pm 0.73$ & $Z=1.4$ & 0.15 \\
\hline & $\mathrm{PaO}_{2} / \mathrm{FiO}_{2}$ & $236.3 \pm 33.73$ & $233.9 \pm 23.05$ & $Z=0.69$ & 0.49 \\
\hline & Inspiratory pressure & $10.97 \pm 1.88$ & $11.05 \pm 1.6$ & $Z=-0.59$ & 0.56 \\
\hline \multicolumn{2}{|l|}{ Time of stay in ICU in days } & $8.38 \pm 1.36$ & $12.03 \pm 6.01$ & $Z=3.04$ & $0.002(S)$ \\
\hline \multicolumn{2}{|c|}{ Time of mechanical ventilation in days } & $5.38 \pm 1.16$ & $9.14 \pm 5.15$ & $Z=3.90$ & $<0.001(\mathrm{HS})$ \\
\hline \multicolumn{2}{|l|}{ Time of starting MV in days } & $1.71 \pm 0.56$ & $1.9 \pm 0.82$ & $t=0.88$ & 0.38 \\
\hline \multicolumn{2}{|c|}{ GFR after $48 \mathrm{~h}$ of admission $\left(\mathrm{ml} / \mathrm{min} / 1.73 \mathrm{~m}^{2}\right)$} & $105.09 \pm 11.36$ & $41.69 \pm 5.75$ & $t=25.88$ & $<0.001(\mathrm{HS})$ \\
\hline
\end{tabular}

APACHE I/ acute physiology and chronic health evaluation II, $A K I$ acute kidney injury, $M V$ mechanical ventilation, GFR glomerular fiteration rate, Vt tidal volume, $R R$ respiratory rate, $\mathrm{PaO}_{2} / \mathrm{FiO}_{2}$ arterial oxygen tension/fraction of inspired oxygen, $I C U$ intensive care unit, $A K I$ acute kidney injury, $P E E P$ positive end-expiratory pressure 


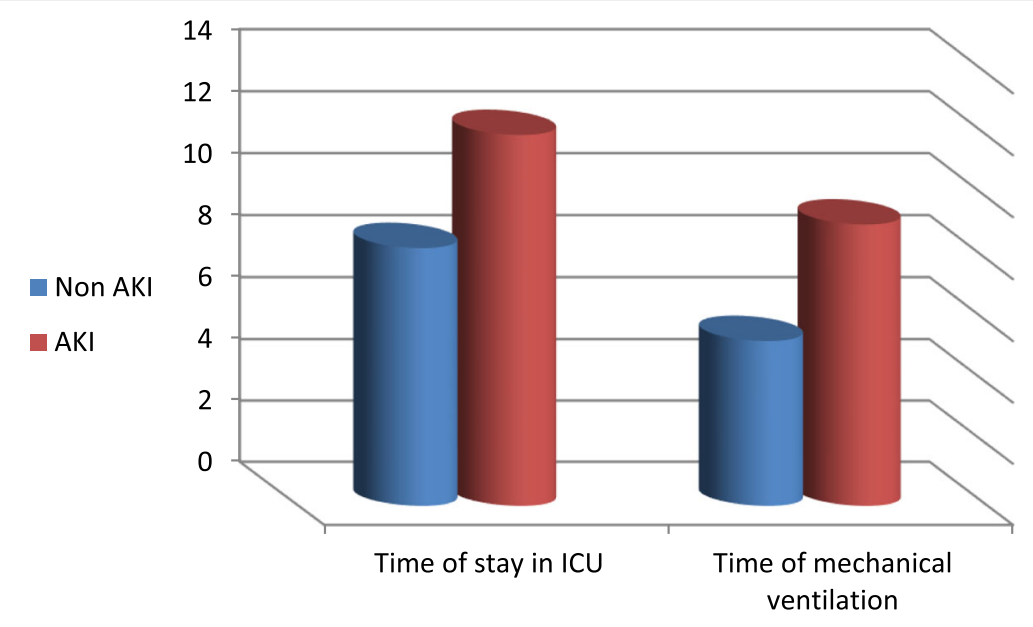

Fig. 1 Time of stay in ICU and on mechanical ventilation (in days) between patients with COPD with and without AKI

However, after adjusting for severity, they still could identify worsening of renal function, defined by an increase of $85 \%$ in $\mathrm{SCr}$, and the occurrence of oliguria, as independent factors associated with prolonged time for weaning. They concluded that in mechanically ventilated older patients, AKI was one of the most important negative predictive factors for ICU outcomes [19].

In this study, it was found that AKI results in a significant increase in required PEEP, ICU stay, and time of MV in days. There is no significant difference between AKI and non-AKI patients as regards time before starting MV, reflecting the effect of AKI on all these parameters (Table 5, Fig. 1).

Amato et al. showed that AKI patients who were weaned from MV indeed used higher PEEPs [20].

Santos and Magro demonstrate the effect PEEP in critically ill patients which can result in altered kidney function in patients in ICU [21]. This is also in agreement with Mehta et al. who explained that a high rate of oliguria and the lower urinary volume in AKI patients probably contributed to positive net fluid balance, confirming recent findings on the effect of fluid balance on weaning [22].

Koyner and Murray showed that there is a bidirectional relationship between the AKI and ALI and shows that injury to one organ may initiate and aggravate an injury to the other. They suggested that this phenomenon might be termed ventilator-induced kidney injury (VIKI) [23].

In this study, there was a significant reduction in GFR in AKI patients after $48 \mathrm{~h}$ of admission than in non-AKI patients, denoting that AKI develops early in susceptible patients after ICU admission or MV start (Table 5).

Elmahallawy and Qora reported that the mean estimated GFR in their COPD group was $75.20 \pm 35.78 \mathrm{ml} /$ $\min / 1.73 \mathrm{~m}^{2}$, while for the control group, it was $92.04 \pm$ $25.54 \mathrm{ml} / \mathrm{min} / 1.73 \mathrm{~m}^{2}$ with a highly significant decrease in GFR in COPD group $(p<0.01)$. The lower GFR in COPD group in their study was attributed to old age with more severe airflow limitation, and $68 \%$ of them had chronic respiratory failure, which points to the susceptibility of COPD patients to AKI [24].

Our study found a significant difference in sonographic findings between the two groups, with increased echogenicity, bilateral grade 1 nephropathy in AKI patients, than non-AKI patients, denoting organic kidney affection not just with functional impairment (Table 6).

Grade I hyperechogenicity was the most important universal finding in acute kidney injury differentiating it from chronic renal failure in a study by Ozmen et al. to evaluate ultrasound in differentiating acute from chronic kidney disease [25].

Table 6 Relation between sonographic findings and kidney injury among the studied groups

\begin{tabular}{|c|c|c|c|c|c|}
\hline \multirow[t]{2}{*}{$\mathrm{U} / \mathrm{S}$ finding after $48 \mathrm{~h}$ of admission } & \multicolumn{2}{|c|}{ Non-AKI (no. = 42) } & \multicolumn{2}{|c|}{ AKI (no. = 58) } & \multirow[t]{2}{*}{$P$} \\
\hline & No. & $\%$ & No. & $\%$ & \\
\hline Normal echogenic kidneys & 42 & 100.0 & 36 & 62.07 & $0.002(S)$ \\
\hline Slight increased echogenicity of the kidneys & 0 & 0.0 & 16 & 27.59 & \\
\hline Bilateral grade 1 nephropathy & 0 & 0.0 & 6 & 10.34 & \\
\hline
\end{tabular}

U/S ultrasonography, AKI acute kidney injury 


\section{Conclusion}

AKI is frequent in COPD patients within $48 \mathrm{~h}$ of ICU admission and mechanical ventilation increase the risk of AKI in COPD patients. Also, assessment of GFR in COPD patients is recommended for early detection and monitoring of renal function abnormalities.

\section{Abbreviations}

AKl: Acute kidney injury; MV: Mechanical ventilation; COPD: Chronic obstructive pulmonary diseases; RF: Respiratory failure; ICU: Intensive care unit; GFR: Glomerular filtration rate; $\mathrm{PaCO}_{2}$ : Arterial tension of carbon dioxide; PH: Power of hydrogen; NIV: Non-invasive ventilation; GOLD: Global initiative for chronic obstructive lung disease; KDIGO: Kidney disease improving global outcomes; CBC: Complete blood count; ABG: Arterial blood gas; Na: Sodium; K: Potassium; CKD-EPI: Chronic kidney disease epidemiology collaboration; MDRD: Modification of diet in renal disease; APACHE II: Acute physiology and chronic health evaluation II; $\mathrm{PaO}_{2}$ : Arterial oxygen tension; $\mathrm{FiO}_{2}$ : Fraction of inspired oxygen; Vt: Tidal volume; RR: Respiratory rate; I:E: Inspiratory/ expiratory; PIP: Peak inspiratory pressure; Pplat: Plateau pressure; PEEP: Positive end-expiratory pressure; Scr: Serum creatinine; ALI: Acute lung injury; VIKI: Ventilator-induced kidney injury

\section{Acknowledgements}

None

\section{Authors' contributions}

AE: design of the work, approval of the submitted version, and agreement to be accountable for the author's own contributions and to ensure that questions related to the work are investigated and resolved; MME: the acquisition and analysis of data, approval of the submitted version, and agreement to be accountable for the author's own contributions and to ensure that questions related to the work are investigated and resolved; TE: interpretation of data, approval of the submitted version, and agreement to be accountable for the author's own contributions and to ensure that questions related to the work are investigated and resolved; SM: creation of new software used in the work, approval of the submitted version, and agreement both to be accountable for the author's own contributions and to ensure that questions related to the work are investigated and resolved; MEE: data curation, draft of the work and substantively its revision, approval of the submitted version, and agreement to be accountable for the author's own contributions and to ensure that questions related to the work are investigated and resolved. The authors have read and approved the manuscript.

\section{Funding}

This research did not receive any specific grant from funding agencies in the public, commercial, or not-for-profit sectors.

\section{Availability of data and materials}

Not applicable.

\section{Ethics approval and consent to participate}

The Research Ethics Committee at the Faculty of Medicine, Benha University, has approved the study, and all patients provided written informed consent before participation. The reference number is not applicable.

\section{Consent for publication}

Not applicable.

\section{Competing interests}

The authors declare that they have no competing interests.

Received: 23 March 2020 Accepted: 21 May 2020

Published online: 21 July 2020

\section{References}

1. Levey AS, Levin A, Kellum JA (2013) Definition and classification of kidney diseases. Am J Kidney Dis 61:686
2. Gopaluni S, Lines S, Lewington AJ (2010) Acute kidney injury in the critically ill patient. CurrAnaestesiaCrit Care 21(2):60-64

3. Ricci $Z$ and Ronco C. Pulmonary/renal interaction. CurrOpinCrit Care.; 16(1): 13-8.Retraction in CurrOpinCrit Care; 2012; 18(3):294.

4. Baver TM, Ritz R, Haberthur C (1995) Prolonged sedation due to accumulation of conjugated metabolites of midazolam. Lancet 346 : 145-147

5. Global Initiative for Chronic Obstructive Lung Disease (GOLD). Global strategy for the diagnosis, management and prevention of chronic obstructive pulmonary disease: 2017 Report. [cited on 2017 Mar 15] Available from: www.goldcopd.org

6. Kellum JA, Lameire N, Aspelin P, Barsoum RS, Burdmann EA, Goldstein SL et al (2012) Kidney disease: improving global outcomes (KDIGO) acute kidney injury work group. KDIGO clinical practice guideline for acute kidney injury. Kidney Int Suppl 2(1):1-138. https://doi.org/10.1038/kisup.2012.1

7. Levey AS, Stevens LA, Schmid CH, Zhang YL, Castro AF, Feldman HI (2009) CKD-EPI (Chronic Kidney Disease Epidemiology Collaboration). A new equation to estimate glomerular filtration rate. Ann Intern Med 150(9):604-612

8. Levey AS, Bosch JP, Lewis JB, Greene T, Rogers N, Roth D (1999) A more accurate method to estimate glomerular filtration rate from serum creatinine a new prediction equation. Modification of Diet in Renal Disease Study Group. Ann Intern Med 130:461-470

9. Knaus WA, Draper EA, Wagner DP, Zimmerman JE (1985) APACHE II: a severity of disease classification system. Critical Care Medicine

10. Ahmed SM, Athar M (2015) Mechanical ventilation in patients with chronic obstructive pulmonary disease and bronchial asthma. Indian J Anaesth. 59(9):589-598. https://doi.org/10.4103/0019-5049.165856

11. StataCorp (2009) Stata statistical software: release 11. StataCorp LP, College Station, TX

12. Cerda J, Lameire N, Eggers P (2008) Epidemiology of acute kidney injury. Clin J Am Soc Nephrol 3(3):881-886

13. Vieira JM, Castro I, Curvello A, Demarzo S, Caruso P, Pastore L Jr et al (2007) Effect of acute kidney injury on weaning from mechanical ventilation in critically ill patients. Crit Care Med. 35(1):184-191

14. Hsu CY, Ordoñez JD, Chertow GM, Fan D, McCulloch CE, Go AS (2008) The risk of acute renal failure in patients with chronic kidney disease. Kidney Int 74(1):101-107

15. Van den Akker JP, Egal M, Groeneveld AB (2013) Invasive mechanical ventilation as a risk factor for acute kidney injury in the critically ill: a systematic review and meta-analysis. Crit Care 17:R98

16. Clermont G, Acker CG, Angus DC (2002) Renal failure in the ICU: comparison of the impact of acute renal failure and end-stage renal disease on ICU outcomes. Kidney Int 62:986-996

17. Pilcher DV, Bailey MJ, Treacher DF, Hamid S, Williams AJ, Davidson AC (2005) Outcomes cost and long term survival of patients referred to a regional weaning centre. Thorax 60:187-190

18. Rothaar RC, Epstein SK (2003) Extubation failure: magnitude of the problem, impact on outcomes, and prevention. CurrOpinCrit Care 9:59-66

19. Esteban A, Anzueto A, FrutosVivar F (2004) Outcome of older patients receiving mechanical ventilation. Intensive Care Med 30:639-646

20. Amato MB, Barbas CS, Medeiros DM (1998) Effect of a protective-ventilation strategy on mortality in the acute respiratory distress syndrome. N Engl J Med 338:347-354

21. Santos LL, Magro MC. Mechanical ventilation and acute kidney injury in patients in the intensive care unit. Acta. Paul. Enferm. 2015; ISSN 1982-0194.

22. Mehta RL, Pascual MT, Soroko S, Chertow GM, PICARD Study Group (2002) Diuretics, mortality, and non-recovery of renal function in acute renal failure. JAMA 288:2547-2553

23. Koyner JL, Murray PT (2010) Mechanical ventilation and the kidney. Blood Purif 29:52-68

24. Elmahallawy IA, Qora MA (2013) Prevalence of chronic renal failure in COPD patients. Egypt J Chest Dis Tuberculosis:62,221-62,227

25. Ozmen CA, Akin D, Bilek SU, Bayrak AH, Senturk S, Nazaroglu H (2010) Ultrasound as a diagnostic tool to differentiate acute from chronic renal failure. ClinNephrol 74(1):46-52

\section{Publisher's Note}

Springer Nature remains neutral with regard to jurisdictional claims in published maps and institutional affiliations. 